\title{
Central Retinal Vein Occlusion Revealing Coeliac Disease
}

\author{
Hana Zoubeidi, Thouraya Ben Salem, Imed Ben Ghorbel, Mohamed Habib Houman \\ Department of Internal Medicine, Rabta Hospital, Tunis, Tunisia
}

Doi: 10.12890/2016_000492-European Journal of Case Reports in Internal Medicine - (c) EFIM 2016

\begin{abstract}
Received: 30/08/2016
Accepted: 05/09/2016

Published: 20/09/2016
\end{abstract}

How to cite this article: Zoubeidi H, Ben Salem T, Ben Ghorbel I, Houman MH. Central retinal vein occlusion revealing coelic disease. EJCRIM 2016;3: doi:10.12890/2016_000492.

Conflicts of Interests: The Authors declare that there are no competing interests.

This article is licensed under a Commons Attribution Non-Commercial 4.0 License

\section{ABSTRACT}

Introduction: Thrombosis has been widely reported in coeliac disease (CD) but central retinal vein occlusion (CRVO) is rarely described. Case presentation: A 27-year-old woman presented with acute visual loss and was diagnosed with CRVO. Her protein S and protein C levels were low and CD was diagnosed on the basis of endoscopic, immunological and histological results. A gluten-free diet resulted in favourable evolution.

Conclusion: $\mathrm{CD}$ should be considered in young patients with thrombosis, especially if in an unusual location. Treatment is based on a glutenfree diet.

\section{LEARNING POINTS}

- Coeliac disease (CD) should be considered in young patients with central retinal vein occlusion (CRVO).

- Several mechanisms can cause thrombosis in CD.

- $\quad$ RVO in CD is often reversible with a gluten-free diet.

\section{KEYWORDS}

Coeliac disease, malabsorption syndromes, retinal vein occlusion, thrombosis

\section{INTRODUCTION}

An association between coeliac disease (CD) and thrombosis has been widely reported in the literature, with different mechanisms proposed to explain an acquired thrombophilic state in subjects with gluten intolerance. Thromboses are mainly seen in unusual locations such as the hepatic, mesenteric and cerebral veins. Central retinal vein occlusion (CRVO) is rarely reported in CD but can reveal the disease. We here describe a new case of CRVO in a patient with CD.

\section{CASE PRESENTATION}

A 27-year-old woman presented with acute visual loss in the right eye without redness or ocular pain. There was no personal or family history of thrombosis. The patient didn't complain of recurrent aphtosis, physical examination was normal and the patient was able to count fingers at $4 \mathrm{~m}$. Fundus examination and fluorescein angiography revealed dilated veins, retinal haemorrhages (Figs. 1 and 2), papilloedema (Fig. 3) and delayed venous filling, suggesting CRVO. Malabsorption syndrome was also noted with iron deficiency anaemia (haemoglobin 5.9 $\mathrm{g} / \mathrm{dl}$ ), hypocalcaemia $(85 \mathrm{mg} / \mathrm{l})$ and hypocholesterolaemia $(0.87 \mathrm{~g} / \mathrm{l})$. Protein C and protein S levels were low at $49 \%$ and $32 \%$, respectively. Antiphospholipid antibodies were negative. Oesophago-gastro-duodenoscopy showed reduced and low duodenal folds. Histopathological 
examination of duodenal biopsies revealed villous atrophy Marsh stage 3 with an increased number of intraepithelial lymphocytes. Antitransglutaminase and anti-endomysial antibodies were negative, but antigliadin antibodies were positive (IgG >100 IU and IgA>100 IU). The diagnosis of CD was made. CRVO was explained by an acquired deficiency in proteins $S$ and $C$ due to a defect in their synthesis related to vitamin $\mathrm{K}$ malabsorption. Implementation of a gluten-free diet and iron supplementation resulted in an improvement in visual acuity to $8 / 10$ and disappearance of the signs of malabsorption.

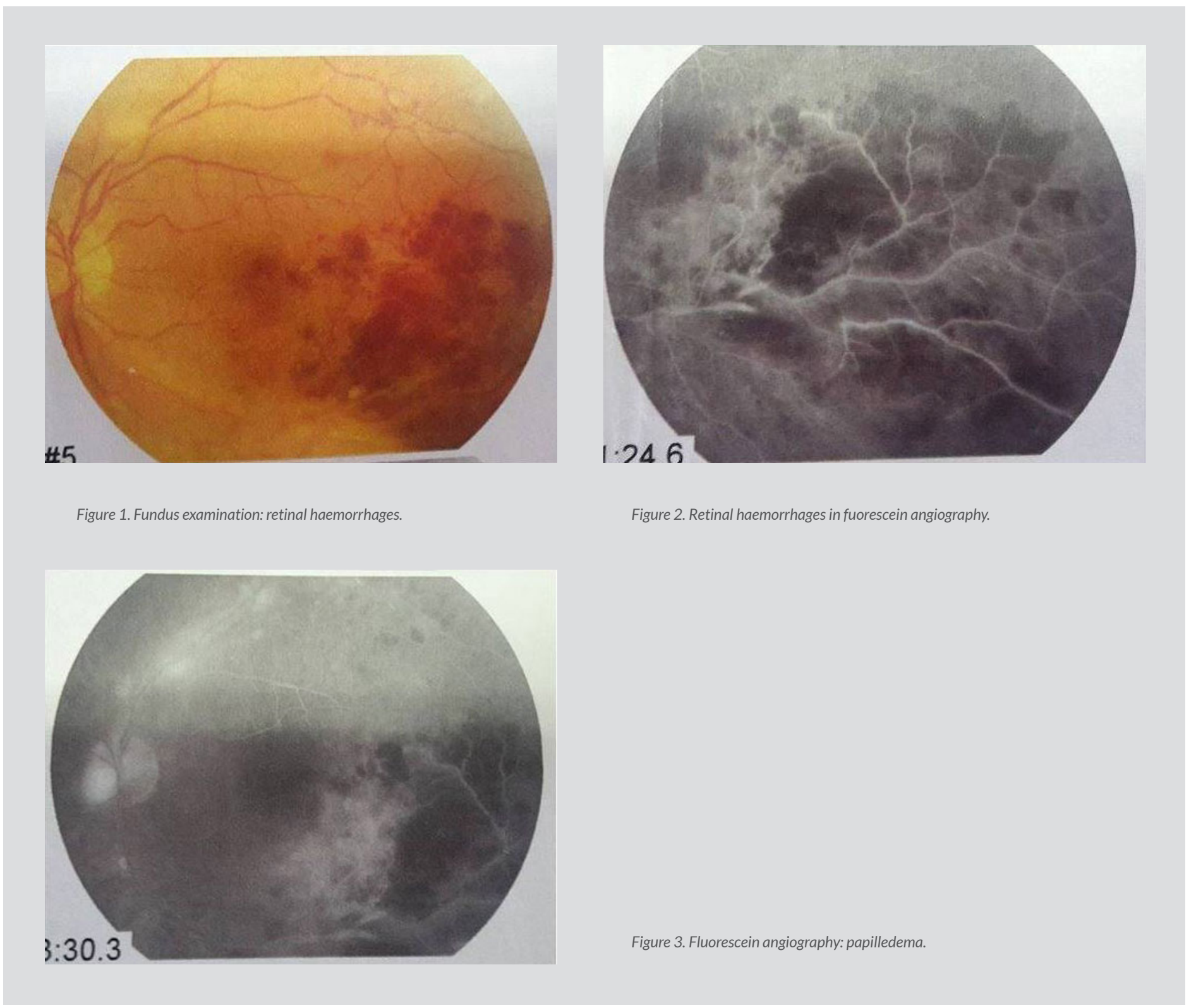

\section{DISCUSSION}

$\mathrm{CD}$ is an autoimmune enteropathy caused by gluten intolerance and usually discovered during childhood. Its clinical profile has been recently updated and the classic symptoms are no longer the most common: CD can be diagnosed in case of fertility disorders, peripheral neuropathy or anaemia ${ }^{[1]}$. Venous thrombosis can also be the first manifestation and reveal CD or may complicate the disease course. Thromboses in CD may be seen in common or in unusual locations ${ }^{[2]}$. CRVO has been occasionally reported in $\mathrm{CD}^{[3-5]}$. The exact physiopathology of $C R V O$ is still 
poorly defined but its multifactorial character is well established. When it occurs in young patients, exhaustive aetiological investigations are required mainly looking for constitutional or acquired thrombophilia. In our patient, the unusual location of thrombosis, the young age and the malabsorption syndrome suggested CD despite the absence of diarrhoea. The diagnosis was made based on blood antibody tests and intestinal biopsies. An increased risk of thrombosis in CD may be caused by a combination of many factors. Malabsorption of vitamin $\mathrm{K}$ leads to a defect in the synthesis of proteins $S$ and $C$ which results in a procoagulant state ${ }^{[2]}$, as described in our patient. On the other hand, folate and vitamin B12 deficiencies may result in hyperhomocysteinaemia with a risk of venous thrombosis ${ }^{[6]}$. Hyperhomocysteinaemia is frequent in $C D$ as attested by a study demonstrating a prevalence of $20 \%$ in patients with recently diagnosed $C D^{[7]}$. Thrombocytosis and endothelial dysfunction have also been incriminated ${ }^{[8,9]}$. Outside these mechanisms, CRVO can be a consequent of hyperviscosity resulting from chronic diarrhoea and malabsorption syndrome ${ }^{[10]}$. At present, the only effective treatment is a lifelong gluten-free-diet which leads to normalization of biological signs, venous repermeabilisation, improvement in visual acuity and disappearance of retinal haemorrhages. CRVO due to CD usually has a good outcome $e^{[3,4]}$.

\section{CONCLUSION}

In young patients, CRVO requires exhaustive investigations for a thrombophilic state. CD should be suspected if there are clinical or biological symptoms such as malabsorption syndrome or iron deficiency anaemia. Resolution of CRVO with a gluten-free diet incites us to evoke the diagnosis of CD.

\section{REFERENCES}

1. Malamut G, Cellier C. Celiac disease. Rev Med Interne 2010;31:428-433.

2. Berthoux E, Fabien N, Chayvialle JA, Ninet J, Durieu I. Adult celiac disease with thrombosis: a case series of seven patients. Role of thrombophilic factors. Rev Med Interne 2011;32:600-604.

3. Lee ES, Pulido JS. Nonischemic central retinal vein occlusion associated with celiac disease. Mayo Clin Proc 2005;80:157.

4. Jomni T, Bellakhal S, Abouda M, Abdelaali I, Douggui H. An atypical presentation of celiac disease: central retinal vein occlusion. Pan Afr Med J 2015;22:300.

5. Wassim H, Wady BJ, Houda L, Besma BA, Kadija B, Hela K et al. Central retinal vein occlusion secondary to celiac disease: a case report. J Fr Ophtalmol 2016:39:e157-159.

6. Ray JG. Meta-analysis of hyperhomocysteinemia as a risk factor for venous thromboembolic disease. Arch Intern Med 1998;158:2101-2106.

7. Saibeni S, Lecchi A, Meucci G, Cattaneo M, Tagliabue L, Rondonotti E, et al. Prevalence of hyperhomocysteinemia in adult gluten-sensitive enteropathy at diagnosis: role of B12, folate, and genetics. Clin Gastroenterol Hepatol 2005;3:574-580.

8. Halfdanarson TR, Litzow MR, Murray JA. Hematologic manifestations of celiac disease. Blood 2007;109:412-421.

9. Lerner A, Blank M. Hypercoagulability in celiac disease-an update. Autoimmun Rev 2014;13:1138-1141.

10. Francis PJ, Stanford MR, Graham EM. Dehydration is a risk factor for central retinal vein occlusion in young patients. Acta Ophthalmol Scand 2003;81:415-416. 